\title{
HYOSCIN AND MORPHIN AS A PRELIMINARY TO LOCAL ANESTHETICS.*
}

\author{
By LeE M. HuRd, M. D.,
}

NEW YoRK.

In 1914, after using this method for nearly two years, I made a report. $\dagger$ Now, in the eighth year, stimulated by the findings of your committee on local anesthetics, reported before this section last year, I am prompted to take up this subject for a second time. Anything that adds to the comfort of the patient, lessens shock and reduces risk of local anesthetic intoxication is surely worth while.

In regard to the report of your committee on local anesthesia: the answers received to the question, "What toxic effects have come under your notice?" thirty-seven in number detail the symptoms of syncope or phrenic.irritation. I consider that all were shock except two or three. The fatalities, excluding the mistakes in dosage, and those cases in which the anesthetic was injected into a vein, appear to me more like mental shock death, and not like fatality from local anesthesia.

The experiments on lower animals, except for toxic dosage, are of no help, because animals experience no apprehension or fear. In the human being, especially in the nervous type, which are in the great majority, apprehension and fear play a very important rôle in shock, even more important than the shock of operative trauma. Not only should the operative field be anesthetized, but the contact ceptors and the special sense ceptors should be blocked.

I wish to state again that the preliminary administration of scopolamin (hyoscin) hydrobromate and, morphin sulphate has eliminated the unpleasant effects of local anesthesia, which I experienced in the past, and given me a confidence that, no

*Read before the Section on Laryngology, Otology and Rhinology of the American Medical Association at the seventy-second annual session, held at Boston, Mass., June 6-10, 1921.

†Hurd, L. M.: Laryngoscope, November, 1914. 
matter how nervous or apprehensive patients may be, there will be no trouble with them at time of operation.

The operations of otolaryngology usually done under local anesthesia are expanded by scopolamin and morphin to the major group, such as mastoidectomies, laryngectomies and resections of the jaw, when general anesthesia is not desired.

\section{DISADVANTAGE.}

Though nearly all patients are ready forty-five minutes after receiving scopolamin and morphin, some require a longer time to settle down, and some require two or three doses. This makes it impossible to appoint a definite time for the operation, as is required in reserving the operating room in a busy hospital. I have had a delay of over two hours in some incidences.

The routine dose is morphin $1 / 4$ grain, scopolamin $1 / 100$ grain. This is usually given after a light meal; if necessary, after forty-five minutes, I administer a second dose, usually half of the first dose, though this depends on whether the patient reacts to one drug more than to the other. If so, less of this is used in the second dose, and more of the less active drug.

In 300 consecutive cases a second dose was given in fortytwo cases; a third dose in five cases, and a fourth dose in two cases. The third and fourth doses were usually given for long major operations. One of my first cases, a woman, became suddenly very hysterical when I was half way through the operation and was noisy, crying, but mainly laughing and noisy for several hours. In her case I had been forewarned of her hysteria; in the hospital, next day, she did not remember the hysterical outburst or any part of the operation. Four other women showed some hysteria when the first tonsil was removed, but gave no cause for complaint when the second came out. I had misjudged my patients and had not given them enough scopolamin and morphin. They probably would have been all right after the second dose.

Two of my early cases (which were mentioned in my previous report), while I was using the sitting position, had marked drop of blood pressure to $90 \mathrm{mg}$. systolic; otherwise 
their condition was good and the operation was finished. In the first case, I gave a hypodermic injection of 10 minims of epinephrin and placed him in a recumbent position. In the second case, after operation, the recumbent position promptly raised the blood pressure. For the last three years all cases have been kept recumbent during the operation, and, even if the dose is not sufficient, syncope and lowered blood pressure do not occur.

Previous to three years ago, the scopolamin I was using did not act as consistently as that which I am using now. There were more cases of delirium, coma, prolonged effect, etc. The scopolamin must be pure; especially, it must not contain apoatropin as an impurity. For the last three years the action of the scopolamin which I have used has been quite as consistent as the action of the morphin. The tablets must be kept dry and fresh. solution made at the time of the operation, as scopolamin in solution will break down into impure and poisonous byproducts in from twenty-four to forty-eight hours.

The patients were nearly all good risks, though the poor surgical risks did as well. When patients are ready for operation, their pulse rate is reduced, they are sleepy or sleeping and do not want to be disturbed, speech is slow and somewhat thick, there is slowed cerebration, they may be somewhat confused, and in moving from bed to operating table they have a staggering gait. Pupils may be contracted (morphin) or dilated (scopolamin). The ideal is midway. The face usually itches, the color is good.

The pulse is taken at the time the patient enters the office for operation, when the operation begins, and immediately it is finished. The average pulse in fifty cases was 99 at the time of entering the office, 85 at the beginning of the operation, and 85 at the end of the operation. This does not, however, show the whole picture; for example, 128, 88,84 in a highly nervous patient, and $76,76,72$ in a phlegmatic one might be taken as extremes.

The blood pressure, which was taken in a few cases a day or two before, at the beginning of the operation and at the end, shows the variations indicated in Table 1. 
TABLE 1. BLOOD PRESSURE.

Before Operation Beginning of Oper'n End of Operation Systolic Diastolic Systolic Diastolic Systolic Diastolic

$\begin{array}{rrrrrr}122 & 76 & 110 & 70 & 124 & 74 \\ 170 & 100 & 180 & 100 & 200 & 110 \\ 150 & 100 & 150 & 104 & 162 & 94 \\ 132 & 84 & 120 & 80 & 150 & 100\end{array}$

The age groups in 300 cases are given in Table 2. Scopolamin and morphin combined work well at all these ages.

TABLE 2. AGE GROUPS IN THREE HUNDRED CASES.

\begin{tabular}{|c|c|c|}
\hline Age & No. of Cases & Percentage \\
\hline From 11 to 20 . & 50 & $16+$ \\
\hline From 20 to 30 . & 75 & 25 \\
\hline From 30 to 40 . & 93 & 31 \\
\hline From 40 to 50 & 50 & $16+$ \\
\hline From 50 to 60 & $\ldots . . .$. & 6 \\
\hline From 60 to 70 & …..... 14 & 5 \\
\hline
\end{tabular}

Having had the usual run of syncopes and varying degrees of psychic shock before I began the use of scopolamin and morphin, I now have none with its use. The patient has a steady pulse, which tends to pass the anesthetic that is being absorbed on to the liver for elimination, preventing intoxication.

Morphin can be used in larger doses if cocain is used in conjunction, and the reverse is true. Scopolamin has the same physiologic action as atropin, plus blocking of the mind. Blocking the sensory nerves with morphin and scopolamin prevents shock, and though more local anesthesia can be used, as a matter of practice less anesthetic is necessary.

The local anesthetics used were : Cocain (topically), twentynine times; procain (hypodermically), forty-one times; alypin (topically), 223 times, and on two occasions no anesthetic was used.

Alypin and procain are quickly eliminated and are, therefore, better than cocain. Alypin, which is as anesthetic as cocain and much less toxic, I prefer, though it is unobtainable at present. Patients are kept in the office two or three hours 
after operation, during which time they are asleep. They are awakened then, and are usually in condition to be taken home. Since the previous report I have extended its use for all cases under local anesthesia, except the very minor and short operations, regardless of age or surgical risk. Whether the patient appears nervous or phlegmatic, I feel confident that if this method is used you will not have the symptoms attributed to anesthetic intoxication and the fatalities with the proper use of the local anesthetic will be greatly reduced.

39 EAST 50TH STREET. 